\title{
Clinical Observation of Minocycline Hydrochloride Ointment in the Treatment of Initial Peri-implant Inflammation
}

BAO TIAN*

Department of Stomatology, Sichuan Academy of Medical Sciences and Sichuan Provincial People's Hospital, Chengdu 610072, China

Tian: Minocycline Hydrochloride Ointment in the Treatment of Peri-implant Inflammation

To observe and analyze the therapeutic efficacy of minocycline hydrochloride ointment in the treatment of initial peri-implant inflammation, a total of 180 patients with initial peri-implant inflammation and treated at the Sichuan Academy of Medical Sciences and Sichuan Provincial People's Hospital were enrolled. The patients were divided into the control group and the research group, with 90 patients in each group. Of those, patients in the research group were applied with minocycline hydrochloride ointment, while $10 \%$ of iodine was placed around the teeth in patients of the control group. The therapeutic outcome was observed and compared between these groups. Comparison of the plaque index of both groups after treatment indicated that the outcome of the research group was better than that of the control group $(\mathrm{P}<0.05)$. The probing depth and sulcus bleeding index of the research group was significantly superior than that of the control group $(\mathrm{P}<\mathbf{0 . 0 5})$. Application of minocycline hydrochloride ointment in the treatment of initial peri-implant inflammation could significantly improve the therapeutic outcome.

Key words: Minocycline hydrochloride ointment, initial peri-implant inflammation, mechanisms, efficacy

Peri-implant inflammation, a reversible inflammation that occurs in the soft tissue surrounding an oral implant, is characterized by redness and swelling of the mucosa, bleeding on probe and even pyorrhea. At present, it is generally believed that the main factors of peri-implant inflammation are closely related to the bacteria on the implant ${ }^{[1,2]}$. That is, due to poor oral hygiene, plaques were piled up around the implant and inflammatory 
response was stimulated. In addition, certain risk factors of peri-implant diseases would also increase the risk of developing this disease. Peri-implant inflammation is a key factor affecting the success rate of oral implant restoration, so it is very important to actively prevent the occurrence of peri-implant inflammation. Periimplant inflammation (fig. 1) is a general term for the pathological state of the implant and surrounding tissues. Studies have shown that peri-implant inflammation is similar to periodontitis subgingival plaque and there is a close association between the implants and the history of periodontitis ${ }^{[3,4]}$. If the patient has a history of periodontitis, the chance of peri-implant inflammation will be significantly increased after $5 \mathrm{y}$. Also, patients with deep periodontal pockets will have a higher chance of peri-implant inflammation. Therefore, it is very important to use active and effective drugs to treat initial peri-implant inflammation. This study was conducted to observe the effect and mechanisms of action of minocycline hydrochloride ointment in the treatment of initial peri-implant inflammation.

A total of 180 patients with initial peri-implant inflammation and treated at the Sichuan Provincial People's Hospital from August 2015 to June 2018 were enrolled. The inclusion criteria were, all those with implant restoration for more than 6 mo and were diagnosed as peri-implant implantation at reexamination (fig. 2). Those with no loose implants, the sulcus bleeding index was 1 or above, the periodontal probing depth was $4 \mathrm{~mm}$ or above, or with a situation of suppuration sinus $^{[5,6]}$. X-rays of the bone-transparent area in the implant are necessary and there should be no systemic disease as well as no antibiotic treatment measures were introduced during the past 3 mo before the study. The exclusion criteria were, pregnant women, lactating women, those allergic to tetracyclines and patients with mental disorders. The formal informed consent was obtained from the patients and their families. The study was approved by the Hospital Ethics Association.

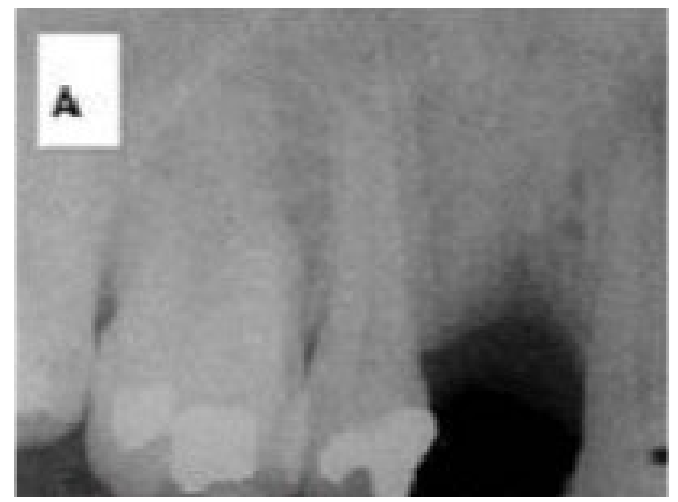

Fig. 1: Peri-implant inflammation

Special Issue 4, 2020

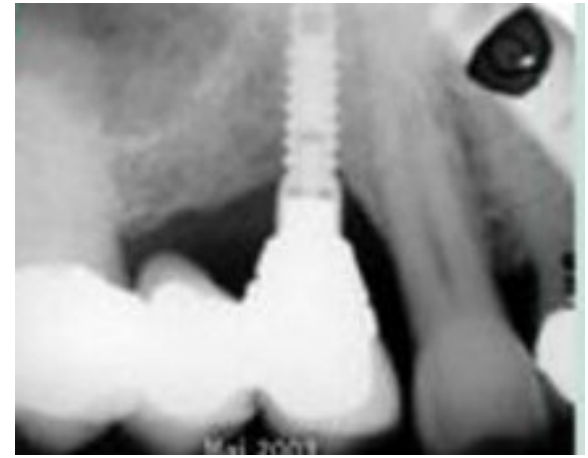

Fig. 2: The image of a patient

Patients were randomized into the research group and the control group with 90 patients in each group. Of those, there were 45 male and 45 female patients in the control group with a total of 102 implants. The average age of the control group was $56.9 \pm 3.2 \mathrm{y}$, ranging from 39-78 y. There were 48 male and 42 female patients in the research group, with a total of 108 implants. The average age of the research group was $55.7 \pm 3.8 \mathrm{y}$, ranging from 42-76 y. Data obtained from both groups were comparable. Different therapeutic regimens were given to patients in both groups, patients in the research group were treated with minocycline hydrochloride ointment, while $10 \%$ of iodine was placed around the teeth in patients of the control group. The periodontal plaque of the implants was removed in control group patients before drug administration and rinsed with saline following the standard procedure. The periodontal pockets were filled with $10 \%$ iodine and placed periodontally once a week. Drinking water and gargle should be avoided within the first $30 \mathrm{~min}$ after taking the medicine and patients were allowed to eat after $1 \mathrm{~h}$. Patients in the research group were treated with minocycline hydrochloride ointment (Japan New Era Co., Ltd., National Pharmaceutical Standard: 20100244) once a week. Minocycline hydrochloride ointment was slowly injected into the periodontal pocket to surround the implant until it overflowed. The other treatments were the same as the control group and both groups were treated continuously for $4 \mathrm{w}$. After treatment, the plaque index (PLI), the sulcus bleeding index (SBI) and the probing depth (PD) of both groups were determined and compared. Among those, PLI scoring was as follows, 0 points- sterile spot, 1 pointif a plaque could be observed on gentle tapping the implant surface with the tip of a plastic probe, 2 pointsif a plaque can be directly seen with naked eye and 3 points- if there is a large plaque ${ }^{[7]}$. The PD is determined by applying the plastic probe with about $20 \mathrm{~g}$ force to estimate the distance from the gingival margin to the periodontal pocket. The SBI was evaluated as follows, 
apply the probe along the implant margin with about $20 \mathrm{~g}$ force, 0 points means no bleeding, 1 point means punctate bleeding while probing and 2 points means bleeding on probing presented as linear, 3 points means severe bleeding on probing. Statistical analysis was performed using SPSS21.0. All quantitative data were expressed in the form of mean \pm standard deviation, and comparisons were made with t-test. Enumeration data were expressed in the form of natural number (n) + percent $(\%)$ and comparisons were made with chisquare test. $\mathrm{P}<0.05$ represented that the intergroup difference was of statistically significance. As shown in Table 1, there was no significant difference in the number of plaques between both groups before treatment, but after different therapeutic methods were adopted, the number of plaques of the research group was significantly less than that of the control group $(\mathrm{P}<0.05)$. After $4 \mathrm{w}$ of treatment, the number of plaques in both groups were increased, but were significantly different from those before treatment $(P<0.05)$. As shown in Table 2, there was no significant difference in the PD between both groups before treatment, but the $\mathrm{PD}$ of the research group at various therapeutic periods were significantly less than that of the control group $(P<0.05)$. After $4 \mathrm{w}$ of treatment, the PD in both groups had gained ascendency, which were significantly different from those before treatment $(P<0.05)$. As shown in Table 3, there was no significant difference

\begin{tabular}{|c|c|c|c|c|}
\hline Time & $\begin{array}{c}\text { Research group } \\
(n=90)\end{array}$ & $\begin{array}{c}\text { Control group } \\
(n=90)\end{array}$ & $\mathrm{t}$ & $P$ \\
\hline $\begin{array}{l}\text { Before } \\
\text { treatment }\end{array}$ & $2.68 \pm 0.55$ & $2.69 \pm 0.47$ & 0.72 & $>0.05$ \\
\hline $\begin{array}{l}2 \mathrm{w} \text { after } \\
\text { treatment }\end{array}$ & $1.68 \pm 0.30$ & $2.04 \pm 0.56$ & 4.28 & $<0.05$ \\
\hline $\begin{array}{l}3 \mathrm{w} \text { after } \\
\text { treatment }\end{array}$ & $1.45 \pm 0.23$ & $1.67 \pm 0.58$ & 4.68 & $<0.05$ \\
\hline $\begin{array}{l}4 \mathrm{w} \text { after } \\
\text { treatment }\end{array}$ & $2.02 \pm 0.21$ & $2.18 \pm 0.50$ & 5.06 & $>0.05$ \\
\hline
\end{tabular}

TABLE 2: COMPARISON OF THE PROBING DEPTH BETWEEN BOTH GROUPS BEFORE AND AFTER TREATMENT

\begin{tabular}{lcccc}
\hline Time & $\begin{array}{c}\text { Research group } \\
(\mathrm{n}=90)\end{array}$ & $\begin{array}{c}\text { Control group } \\
(\mathrm{n}=90)\end{array}$ & $\mathrm{t}$ & $P$ \\
\hline $\begin{array}{l}\text { Before } \\
\text { treatment }\end{array}$ & $4.10 \pm 0.52$ & $4.16 \pm 0.40$ & 0.66 & $>0.05$ \\
$2 \mathrm{w}$ after & $3.12 \pm 0.28$ & $3.69 \pm 0.51$ & 5.60 & $<0.05$ \\
treatment & & & & \\
$\begin{array}{l}3 \mathrm{w} \text { after } \\
\text { treatment }\end{array}$ & $2.78 \pm 0.19$ & $3.26 \pm 0.49$ & 5.07 & $<0.05$ \\
$\begin{array}{l}4 \mathrm{w} \text { after } \\
\text { treatment }\end{array}$ & $3.62 \pm 0.22$ & $3.79 \pm 0.50$ & 4.23 & $>0.05$ \\
\hline
\end{tabular}

TABLE 3: COMPARISON OF THE SULCUS BLEEDING INDEX BETWEEN BOTH GROUPS BEFORE AND AFTER TREATMENT

\begin{tabular}{lcccc}
\hline Time & $\begin{array}{c}\text { Research } \\
\text { group } \\
(\mathrm{n}=90)\end{array}$ & $\begin{array}{c}\text { Control } \\
\text { group } \\
(\mathrm{n}=90)\end{array}$ & $\mathrm{t}$ & $\boldsymbol{P}$ \\
\hline $\begin{array}{l}\text { Before treatment } \\
2 \mathrm{w} \text { after }\end{array}$ & $4.39 \pm 0.46$ & $4.28 \pm 0.22$ & 0.59 & $>0.05$ \\
$\begin{array}{l}\text { treatment } \\
3 \text { w after }\end{array}$ & $1.59 \pm 0.27$ & $3.48 \pm 0.36$ & $4.30<0.05$ \\
$\begin{array}{l}\text { treatment } \\
4 \text { w after } \\
\text { treatment }\end{array}$ & $1.42 \pm 0.18$ & $3.17 \pm 0.57$ & $6.08<0.05$ \\
\hline
\end{tabular}

in the SBI between both groups before treatment. But the SBI of the research group at various therapeutic periods was significantly decreased than that of the control group $(P<0.05)$. After $4 \mathrm{w}$ of treatment, the SBI in both groups had gained ascendency, which were still significantly different from those before treatment $(P<0.05)$. A case of bleeding on probing was shown in fig. 3.

Peri-implant inflammation is a major complication in the course of implant treatment, which is closely related to the patient's poor oral hygiene and poor oral habits. Mainly caused by the failure of synostosis induced by infection, peri-implant inflammation is characterized by mucosal inflammatory hyperplasia, abscess and fistula around the implant. The progression of inflammation can cause bone loss around the implant and eventually lead to implant failure ${ }^{[7,8]}$. Timely and effective treatment of peri-implant inflammation is an important guarantee for improving patients' life quality. Minocycline hydrochloride ointment can exert a high affinity to bone tissue, actively inhibit collagenase activity and reduce the degree of damage to periodontal tissues, thus promoting periodontal tissue regeneration ${ }^{[9-13]}$. The underlying mechanism is to inhibit the bacterial protein synthesis and exert antibacterial effects against staphylococcal, Escherichia coli and the gram-negative bacteria in the subgingival plaque, thus leading to favorable improvement on the various symptoms of periodontitis. Minocycline is a semi-synthetic tetracycline with a longer lasting, broad spectrum antibacterial activity that can penetrate well. Moreover, the ointment can slowly release minocycline in to the periodontal pocket. In the presence of water, the ointment will harden and produce a film-like substance, so that the local drug concentration could be maintained at high level for $5 \mathrm{~d}$ to $1 \mathrm{w}$. Therefore, the application of minocycline hydrochloride ointment can significantly improve the function by fully exerting the 
www.ijpsonline.com

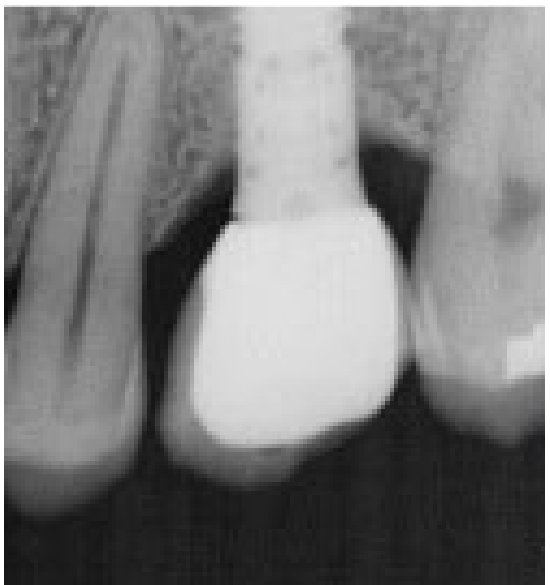

Fig. 3: A case of bleeding on probing in a patient with peri-implant inflammation (probing depth 4-5 $\mathrm{mm}$ )

therapeutic effects ${ }^{[14-16]}$.

Results from this study showed that the improvement of PLI, PD and SBI of the research group after treatment was significantly superior than that of the control group $(P<0.05)$, which is consistent with previous reports. In conclusion, during the treatment of early peri-implantitis, minocycline hydrochloride ointment could be used to improve the treatment outcome and promote good recovery of patients. Periimplantitis is a key factor affecting the success rate of dental implant repair, so it is very important to actively prevent the occurrence of peri-implantitis. The reason why minocycline hydrochloride ointment could achieve sound therapeutic effect for peri-implantitis is that the minocycline hydrochloride could exert high affinity to bone tissue, and actively inhibit the activity of collagenase, reduce the degree of destruction of periodontal tissue, and then promote the regeneration of periodontal tissue. In addition, minocycline, a semisynthetic tetracycline, could exert longer lasting broad spectrum antibacterial activity with high penetration, which significantly enhances the therapeutic effect. The application of minocycline hydrochloride in the treatment of peri-implantitis has good applicability, and larger studies are needed to support the clinical efficacy of minocycline ointment.

\section{REFERENCES}

1. Zhu JF, Liu L, Xiao Y, Li WL, Yang YJ, Liu B. Evidence -based medicine study on treatment of peri-implantitis with minocycline. Henan Med Res 2015;24(02):17-20.

2. Li L, Ma JH, Wu YF. Clinical study on Minocycline Hydrochloride Ointment in treatment of chronic periodontitis. Drugs and Clinic 2015;30(05):531-4.

3. Wroblewska K, Kucinska M, Murias M, Lulek J. Characterization of new eye drops with choline salicylate and assessment of their irritancy by in vitro short time exposure tests. Saudi Pharm J 2015;23(4):407-12.
4. Abdel Moty MS, Hussein MA, Abdel Aziz SA, Abou-Salim MA. Design and synthesis of some substituted thiazolo [3, 2-a] pyrimidine derivatives of potential biological activities. Saudi Pharm J 2016;24(2):119-32.

5. Hazra M, Mandal DD, Mandal T, Bhuniya S, Ghosh M. Designing polymeric microparticulate drug delivery system for hydrophobic drug quercetin. Saudi Pharm J 2015;23(4):42936.

6. Zheng Q, Sun WP, Zhou SZ. Clinical application effect of minocycline hydrochloride ointment in severe chronic periodontitis. Chinese J Biochem Pharm 2016;36(03):34-6.

7. Liu SX, Zheng ZP, Mao XQ. Application of minocycline hydrochloride in peri-implantitis. Hainan Medicine 2016;27(20):3379-82.

8. Chen D. Effect of Nd: YAG laser-assisted minocycline hydrochloride ointment on early peri-implantitis. The Department of Oral Medicine Electronic Magazine (Electronic edn.) 2017;4(08):24-5.

9. Ofori-Kwakye K, Mfoafo KA, Kipo SL, Kuntworbe N, Boakye-Gyasi ME. Development and evaluation of natural gum-based extended release matrix tablets of two model drugs of different water solubilities by direct compression. Saudi Pharm J 2016;24(1):82-91.

10. Attari Z, Bhandari A, Jagadish PC, Lewis S. Enhanced ex vivo intestinal absorption of olmesartan medoxomil nanosuspension: Preparation by combinative technology. Saudi Pharm J 2016;24(1):57-63.

11. Wang L, Ge S, Liu Z, Zhou Y, Yang X, Yang W, et al. Properties of antibacterial bioboard from bamboo macromolecule by hot press. Saudi J Biol Sci 2018;25(3):465-8.

12. Chen Y, Liu L, Zhou Q, Imam MU, Cai J, Wang Y, et al. Body mass index had different effects on premenopausal and postmenopausal breast cancer risks: A dose-response metaanalysis with 3,318,796 subjects from 31 cohort studies. BMC Public Health 2017;17:936.

13. Rehman N, Orakzai MB, Hayat A, Azam S, Ahmad B, Khan I, et al. Prevalence of hepatitis c virus and its risk factors in blood donors in district peshawar. Pak J Pharm Sci 2018;31(1):83-7.

14. Podolsky IM, Shtrygol' SY, Zubkov VO. The psycho- and neurotropic profiling of novel 3-(n-r, $r$ '-aminomethyl)2-methyl-1h-quinolin-4-ones in vivo. Saudi Pharm J 2018;26(1):107-114.

15. Temizi A, Ozdemir Y, Aslan A, Bostanci MT, Atasoy G, Caparlar MA, et al. Role of complete blood counts parameters in diagnosis of acute cholecystitis. Acta Medica Mediterr 2017;33(3):411-6.

16. Yadav KD, Chaudhary AK, Verma AK. Bioavailability enhancement of partially water soluble solid medicament in traditional system of medicine. Indian $\mathrm{J}$ Pharm Sci 2017;79(5):667-73.

This is an open access article distributed under the terms of the Creative Commons Attribution-NonCommercial-ShareAlike 3.0 License, which allows others to remix, tweak, and build upon the work non-commercially, as long as the author is credited and the new creations are licensed under the identical terms

This article was originally published in a special
issue: Special issue on "Animal Models \& Experimental
Medicine"
Indian J Pharm Sci 2020:82(1)spl issue4;60-63

